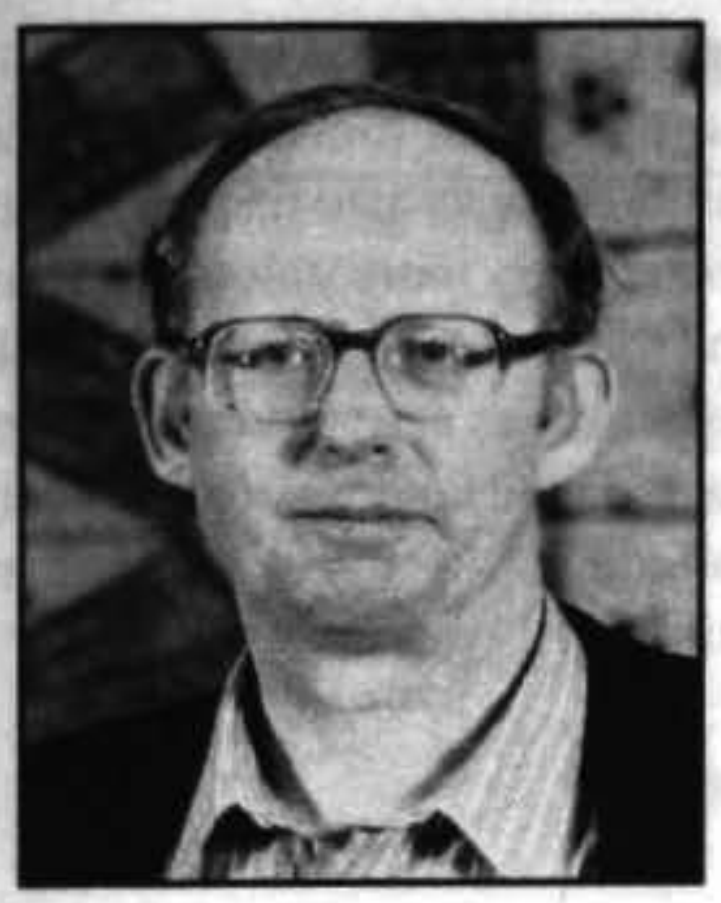

\title{
THE ROLE OF WORKPLACE \\ CONTESTS IN NEW ZEALAND
}

Rupert Tipples $^{1}$

Applied Management and Computing Division

Lincoln University

Contests have played a major part in New Zealand's economic development since colonisation. They are part of the New Zealand psyche. After defining contests, this paper discusses the range and place of contests in economic development and the underlying theoretical concepts. How contests are used, operate in practice, and their benefits, are discussed by means of case studies based on both documentary sources and participant's accounts. The setting up and operation of contests is considered, together with the part played the various stakeholders in any particular contest. Conclusions are drawn on the features needed to prolong their usefulness and longevity.

Keywords: Contests, stakeholders

The term contest is used here in two ways, to describe competitions and awards as events. These represent two ends of a continuum; competition being the competitive display of work related skills over a short time, and the term award describing the prize winner's superior performance over a (usually) longer period. The skills and knowledge used in a competition are directly observable, unlike awards that are usually an acknowledgement or celebration of excellence and not directly observable. However, neither case is mutually exclusive and there are frequent overlaps for specific contests. Some awards could be seen as being largely driven by capitalist tendencies. Junior Achievement, which has operated in the USA since 1919. has been seen as helping kids dream and providing the tools they need to bring those dreams to reality. Affecting some 30 million young people in that time, it has helped educate them and "....inspire them to value free enterprise, business and economics to improve the quality of their lives." (http://www:ja.org/aboutJA/index.asp )

The ideas explored in this case study of contests in New Zealand as ways to facilitate the learning of skills and knowledge are rooted in examples of contests currently or recently operating. The paper has an agricultural bias resulting from the author's primary field of interest, which is believed to be appropriate as a reflection of the significance of agriculture to the New Zealand economy.

The usefulness of contests as a means of agricultural education and extension has long been recognised but comparatively little has been written about it. In the F.A.O.'s Agricultural Extension - A Reference Manual only a brief description is given of what the F.A.O. perceives to be the rationale of contests:
Contests are based upon the principle of competition and community oriented activities, to encourage participation and heighten practical agricultural skills. The purpose of holding contests is to provide farmers, especially young farmers, with powerful motivational forces and to offer opportunities to excel in specialized subjects and skill areas...Entering contests. shows, exhibits and demonstrations is encouraged by offering awards and rewards (Swanson, 1984, p. 136).

However, that does not explain the theoretical rationale for contests, nor why they should be so successful in New Zealand. To answer those questions we need to reflect on the nature of competition and the New Zealand psyche.

\section{Competition}

Handy (1985) considers that competition as a process has three positive features: competition sets standards; it stimulates and channels energy; and lastly it sorts out better performance from poorer. Status is based on the distribution of prestige, which can be valuable to a contestant seeking to highlight their superiority over their competitors:

In other words, the possession of the title or the symbols of an achiever ensures general social recognition. This relationship holds for every kind of occupational achievement; success in the labour market implies a high social status and a conscious. ness of one's own ability to succeed (Rigauer, 1981:26). 
If motivation is considered a state where the individual is energised with respect to a specific purpose or goal (Deci \& Ryan, 1985), the underlying processes that make up this state are just as important. Motivation has also been described as "...a set of processes concerned with the force that energises behaviour and directs it toward obtaining some goal" (Baron, 1983). Also Rigauer (1981) writes that:

\section{In both work and sport, the struggle of competi- tion demonstrates the same socially determined aspects: competition promises gains in personal prestige and in the recognition which follows success in one's occupational activity...one is worth something (p.25)}

Lowe et al. (1992) reviewing the achievements of New Zealand's Tui Dairy Farmer of the Year Competition concluded that the competition, in conjunction with field days, was a useful educator promoting adoption of a business approach to dairy farming. They concluded that:

\begin{abstract}
...the competition has a strategic role in the development of a strong dairy industry by demonstrating to investors, existing and future suppliers, financiers, dairy company directors and job seekers the relative merits of dairy farming as a business to measure against competing opportunities (p.83).
\end{abstract}

Other benefits have been said to include improved performance and greater contacts across the industry, as well as increased experience and new skills learned (Farrar, 1977; McDougall, 1995).

Often contests have a variety of stakeholders in their benefits. Owners or employers, corporate sponsors, advertisers, media personnel, marketing and publicity staff, and professional managers, accountants and agents can all have an active role into these contests (Coakley, 1990). There is often a degree of governmental participation. The nature of this stakeholder participation is usually economic support for the competition, either through money or sponsorship. For these stakeholders this is an investment in something considered as:

1. Intangible - seen but not sensed by taste, touch or smell.

2. Perishable - the event has little lasting value.

3. Sold, delivered, consumed, immediately.

4. Heterogeneous - no two are alike.

5. Incapable of ownership - brand loyalty to the event is not possible (Shuttleworth, 1990, adapted by Tipples).

However, the continued support by the various stakeholders suggests that from a commercial perspective there are definite benefits attached to contests. The benefits may be tangible, for example, increased product sales arising from the competition. This may be simply due to the exposure of a brand name or it may due to the spectators wishing to emulate the winners by using similar tools. As well as such direct economic benefits contests also have other intangible benefits that are potentially more valuable. Contests offer associated sponsors a valuable form of profile raising. By showing the sponsors as active within the local community and being associated with what are usually fun events, contests can offer a very positive and human side to a faceless corporation.

\section{The New Zealand Psyche}

New Zealand has been described as having a strong sport focus and a fairly competitive culture (Cushman, 1989). Hofstede (1994) has compared masculine attributes within a culture (e.g. assertiveness and competition) and rated New Zealand as the 17 th most masculine culture studied behind countries such as Japan (1st), Mexico (6th), Britain and Germany (9th=), the USA (15th), and Australia (16th) but ahead of France (35th=), Denmark, Netherlands, Norway and Sweden (50th-53rd respectively). New Zealand's competitive culture appears to be largely an inheritance from its European ancestors, but is also a feature of pre-colonial Maori culture (Armstrong, 1986). A reason suggested for this competitive culture has been the "pioneering spirit' of the early settlers. This spirit is shared by many farmers the world over. It includes a number of frontier value themes characteristic of a pioneering society: competitiveness is individually useful and socially desirable; individual initiative and independence of action lead to success; individuals should seek maximal individual autonomy and control over their environment; masculinity implies toughness; aggressiveness and the ability to withstand stress; and challenge and excitement should be actively sought. Risk taking is justified in the meeting of challenge (Klein, 1971, in Cushman, 1989:138).

These early influences have led to a society where children can be involved in school agricultural competitions from as early as the age of five. These can be simple competitions in rural schools involving pets (lambs, calves, cats and dogs etc.), through to more serious international competitions in senior schools, e.g. the Maths and Computing Olympiads and the World Debating Championships. Examples of contests in three productive sections together with an 'entrpreneurial mixed' are shown in Table 1. To understand the operation of New Zealand's competitive culture better a more detailed study is now made of five different contests.

\section{Contests and the Young Farmers' Club Movement}

Agricultural improvement in New Zealand was initially addressed by the Agricultural and Pastoral Societies. Table 2, placed at the end of this paper, offers several exaples of agricultural contests. The first settlers in Canterbury (1850) formed their first Agricultural and Pastoral Association (1859) which was short lived. A more permanent A and P Society based in Christchurch held it first Show 
Table.1 Examples of New Zealand Contests

\begin{tabular}{lll}
\hline Sector of the economy & Competitions & Awards
\end{tabular}

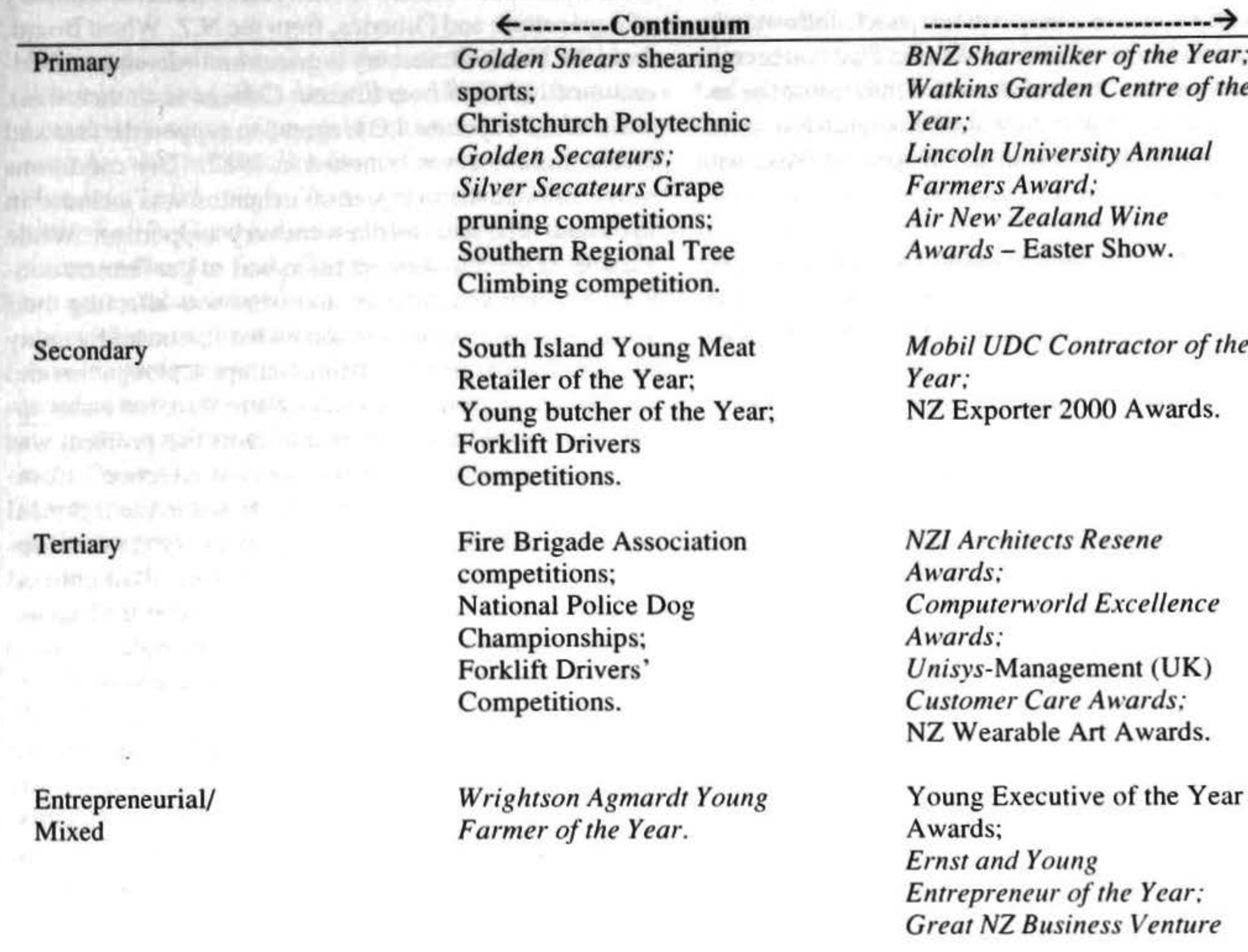

and contests in 1862 (Lyttelton Times, 25 October 1862). The first agricultural teaching institution was Lincoln College founded in 1878. Then in 1892 the first Liberal Government (1890-1911) set up the Department of Agriculture to provide farmers with expert scientific advice to improve the quantity and quality of agricultural production. In 1918 the first agricultural clubs were formed in general schools and based around crop growing competitions (swedes, turnips and potatoes) and calf rearing. Agricultural instructors of the Departments of Agriculture and Education worked jointly in judging, teaching and organising the work of the clubs (Wards, 1963).

The Federation of Young Farmers' Clubs grew from a club founded at Palmerston in Otago in November 1932 at the height of the interwar depression. While similar organisations were being founded in Britain and Australia about the same time, that appears to have had no influence on developments in New Zealand (ibid., p.239). Chance remarks led to a farmer and farm instructor putting together the critical ideas and implementing them. They were supported by educational personnel who had been involved in the agricultural clubs at schools and saw the potential of young farmers clubs for post-school rural youth. Then the general manager of the local farmers' mutual fire insurance company became involved. He organised a Young
Farmers Education Week for the province during which he publicised the new clubs and made an appeal to those present to take the initiative in founding clubs in their home districts. Later he became the first Dominion President of the Dominion YFC Federation. He could see that despite the desperate economic situation the movement would be of direct benefit to rural young men. It would also be valuable for the community. Partly as a counter to the loss of direct state support, because of the depression, the Federation of Young Farmers Clubs, was set up with its own constitution, office bearers and rules. By April, 1937, there were 60 clubs in the South and 58 in the North Islands. Competitions, which were continued from school agricultural clubs, were a central activity of YFC and in November, 1937, the first national stock judging competition took place (ibid, p. 243).

A number of lessons can be drawn from this early history. First, there must be a real need. In the days before television YFC provided a convivial social gathering for rural youth, which built up the community and developed future leaders. Secondly, they also had the backing of their seniors who perceived the opportunities and offered wise advice. Today the Wrinklies continue to offer that sage advice with their greater experience and wisdom. For a movement which keeps losing their leadership as they at- 
tain 30 this is a valuable resource. Thirdly, they had inspired sponsors who supported the work. The inspired individuals of the 1930s have been replaced by the range of equally significant corporate sponsors whose names are exhibited in the list of competitions which follows who back their vocal support with hard cash. That has become extra important since the withdrawal of farm subsidies and "user-pays" of the 1980s. Now the Federation has to survive by its own wits and with the support of those with mutual interests.

The New Zealand government was a stakeholder in the development of the Golden Shears Shearing Championships. The ideas behind the establishment of the Golden Shears stemmed in part from the competitive tendencies of the Young Farmers Movement and the major economic significance that wool production played in New Zealand's economy post 1945. This was manifested in the Department of Agriculture's emphasis on shearing instruction for young men, with the aim of improving the presentation of the wool clip and skills associated with shearing and wool handling (Williams and Way, 1991).

When the Federation published a Yearbook in 1991-2, competitions still featured as a major element of YFC's activities. There were listed there: Dow Elanco National Debating Competition, Agrisales-Trutest National Stock judging, the Public Speaking Competition, Wool Board National Shearing and Woolhandling Teams Competition, the Dr L.W. McCaskill Community Award, the A.C.C. Matheson Trophy for contributions to rural safety, the Bernina Make ' $n$ ' Model Competition, the F.M.G. Writers Award, and the YFC Photography, Achievers and Publicity Awards, as well the then Skellerup Young Farmer of the Year Contest. The latter has been the public view of YFC activities now for nearly 20 years as the final has been televised live at prime time on a Saturday evening. Agriculture has been presented to

\section{... a largely urban audience as a technicaliy demanding business, and young farmers as a group of highly intelligent and motivated people (YFC Yearbook 1991-2).}

YFC does offer big social occasions but also the chance to try out new challenges, and the chance to be continually stretched..

\section{Setting up Contests}

For any contest to be set up there has to be the original idea, which has to grab the public imagination. Then participants are forthcoming. Also, for the idea to get off the ground it usually has to have a champion, who will promote it and gather the team together which is necessary to make it work. For the ICI Wheat Growing Award the key instigator was an academic colleague who observed individual grower plots at a field day at the Royal Agricultural College (Cirencester, England) while on Study Leave in 1979. He perceived the potential for a competition and helped set up the team to put the idea into effect. The team consisted of representatives from Crop Research Division, Department of Scientific and Industrial Research; from Federated Farmers of N.Z. (Inc.), from the Ministry of Agriculture and Fisheries, from the N.Z. Wheat Board, from the North Canterbury Agricultural Merchants' Federation (Inc.), and from Lincoln College (as it then was). A significant sponsor, I.C.I. agreed to support the idea and the first contest was launched in 1982. Dry conditions nearly aborted the first year, so irrigation was included in the rules. The local media were very supportive. While the aim of the initial competition was to get farmers considering their wheat crops, and what was affecting their yields, the organisers were somewhat frustrated by many of the earliest competitors being champion ploughmen and not top wheat growers. Because there were too many applicants for the limited number of plots this problem was overcome subsequently by a process of selection. Competing growers had to become interested in the technical aspects of the subject such as the timing of the development of the yield components of the crop. That grasped the cropping public's imagination too, and at the best associated field day the paying attenders were equal to nearly half of New Zealand's population of wheat growers.

Interest began to fall off after three years and the contest went out of Canterbury briefly. When it returned it was broadened to cover all cereals to add interest, and then to all types of cropping. By this stage it seemed to have lost the drive of its initiator. Wheat was his primary interest and it had achieved its aims and farmers were thinking like wheat scientists in terms of the factors affecting yields. To quote him: "It had been a lot of bloody fun!" So the last contest was held in 1989.

\section{The Silver Secateurs}

To provide a recent example of a new contest, the establishment of the Silver Secateurs competition for grape pruners, begun in 1995, is described. The New Zealand Grapegrowing Council had decided to celebrate the 100th anniversary of the visit of viticulturist Romeo Bragato. There was an associated Field Day, with grape pruning competitions. The idea for the competitions came from a Marlborough grape grower who had previously been associated with the Golden Shears shearing competitions. The competition aimed to feature the contribution of the industry's workers; their skills and abilities; and to help employers to know the best individuals and teams. It was also to highlight the significance of the pruners; and to give recognition to the quality of work and pride in the job for a group of people who are largely casual and seasonal workers. The competition was instigated partly in recognition that future skill shortages could impede industry development with the expansion of the vineyard area (Winepress, 40, 1995). Both individual and teams events were established, with competitors required to prune six vines, of which one was to be in front of the judges. Teams had three roles - pruner, stripper and tier. Individuals were also required to answer ten multi-choice ques- 
tions and answer any questions the judges might have had while they were pruning the 'observed' vine. There were 45 individual pruners and tiers in the first year of competition and fifteen teams.

Judging proved to be one of the unanticipated problems. What was a good job? According to Dr David Jackson, a Lincoln University grape growing expert: “...a good pruner must be able to visualize how to prune each individual element..." of the vine. "It was at least as skilled as sheep shearing...". Good judges were key people in the competitions and hard to find. Commercially, pruning standards are set by what the owner wants, but opinions are varied about what is required for ongoing quality production rather than immediate quantity. Competitors needed to be advised of how many canes the owner wanted left. Variability in the condition of the wood was a further complication. Quite a lot of time was taken by the judging process. It was based around Californian College experiences with such competitions and used related scoring sheets. Pruners were briefed as the competitions began, but communications were not perfect and an improved briefing was decided upon as a requirement for future years. One aim of the competition was to enhance quality and not speed. In any event the first to finish were not usually the final winners. In 1997, for the first time, competitors were given a scorecard with their marks to indicate areas needing improvement. Animated discussion between growers and pruners followed, commenting on what had been done and where improvements could be made.

As a public spectacle the competitions proved somewhat disappointing. The row form of vineyards was the problem. Spectators could not see easily and were frustrated because they were seriously interested in seeing what was happening. Crowds were particularly a problem at the teams event and to some extent interfered with contestants. Some spectators were there to see the spectacle, some were there as supporters for contestants, and some were there to learn all they could about pruning.

Sponsorship was provided by a manufacturer of pruning equipment. The first prize was \$NZ 600, with \$NZ 450 for second and \$NZ 400 for the teams event, showing that prizes do not have to be large for these events. Subsequently equipment suppliers offered substantial discounts to purchasers at the event. One refinement introduced in 1997 and 1998 was to prejudge the vines before and after the event to give a better indication of the skills of the competitors, and to account for uneven vines (Winepress, 69,1998 ). The competitions have become an ongoing event. Being part of a high profile, expanding industry has clearly also played a major part in the success of the Silver Secateurs. Grapes and wine seem to have that certain cachet that draws public attention.

\section{Prolonging Contest Longevity}

To retain public interest is a major problem. Some contests have attained a cult status of their own. The Golden
Shears is the top shearing competition in the world for many and in 2,000 celebrated its fortieth anniversary with a major gathering of former contestants. The competitive strain still drives young farmers throughout New Zealand and its major competition, the Wrightson Agmardt Young Farmer of the Year, has recently survived a major change of sponsors with undiminished fervour. It provides much more meaningful competition than the average television game show. Also, competitors only have a limited life as they can no longer compete after the age of thirty, so there is a regular changeover. On the other hand, the current Golden Shears champion, David Fagan, has won the top shearing event eleven times, ten in succession. Yet no one has suggested that it is becoming boring!

One way of retaining interest is shown by the Lincoln University Foundation Rabobank Annual Farmers' Award which changes its subject each year. It has exhibited a willingness to be adventurous in choosing topics which challenge farmers' entrepreneurial and innovative tendencies. In 1998 they called for Premier suppliers supplying superior product as defined by contract to a processor or retailer for a price premium, or who had direct marketed on their own behalf. The winners had developed a fresh culinary herb venture from a core farming enterprise of dairy farming. In the words of the coordinating judge, the subject had produced a "...showcase of imagination, lateral thinking and entrepreneurial talent". It resulted in a record number of entries in the 16 year history of the award. In 1999 the subject was "Excellence in Innovation" with the aim of finding farmers who had recognised opportunities to break free from traditional methods of commodity production by responding positively to changing market demands and opportunities. Less rose to the challenge, but the topic overlapped with the previous year's, and historically numbers have always oscillated from year to year.

Another recent contest encouraging entrepreneurial activity with substantial prizes (e.g. First and Second prize: 2 @ \$60,000; Third and Fourth prizes: $2 @ \$ 40,000$ ) has been the Great New Zealand Business Venture sponsored by ASB Bank, Carter Holt Harvey, Deutsche Bank, and Deloitte Touche Tohmatsu, amongst others, which has operated during 2000. The manager of the competition, Bridget Wickham, said: "...the competition aims to create viable businesses in New Zealand, assist in the development of support networks for small businesses and promote an entrepreneurial spirit in this country." (NZ Educational Review, 24 March 2000). Response to the competition was overwhelming with over 300 entries in the first two weeks (Ref: http://www.greatventure.co.nz/pages/ homesm.htm).

\section{Conclusion}

So, what may we conclude? Contests in New Zealand are popular and well supported events, having educational. motivational, sport and leisure components and benefits. The extent to which they facilitate learning is difficult to assess but the advantages are described very positively by 
all parties. All the stakeholders in a contest have to benefit from that contest either directly or indirectly, spectators included, for it to have lasting value. Only then is contest longevity assured. However, when they are successful and grasp the public imagination, like the Golden Shears, they can become a sport event just as much as test matches for cricket, netball or rugby, able to attract the crowds and ongoing interest. They can even become an 'industry' in their own right. Masterton, a small sleepy town in the Wairarapa, now proudly advertises itself as "Home of the Golden Shears".

\section{Future Research}

Three areas for future research are apparent. First, publication of this research does not seem to meet the editorial requirements of European editors because it is seen as theoretically 'thin'. The pragmatic approach of New Zealanders ... because contests work is seen as inadequate and therefore not worthy of publication. Consequently, developing an adequate theoretical basis for the study of contests has become urgent. Secondly, there is considerable scope for further documenting the nature and extent of contests in the secondary and tertiary sectors of the economy. The examples provided in Tables 1 and 2 are known to provide only a partial picture of the range of contests operating in New Zealand. Thirdly, there is the opportunity for further elaboration of the pre-conditions contests have to achieve to provide educational, motivational and recreational benefits to their respective stakeholders.

\section{Notes}

1 Paul Jones made substantial contributions to this re search on contests and to early drafts of our original paper. His contribution was funded by a grant from the Research Committee, Applied Management and Computing Division, Lincoln, University.

2 In this paper agriculture is used in the American sense as including horticulture.

\section{References}

Armstrong, A. (1986) Games and Dances of the Maori People. Wellington, NZ: Viking Sevenseas.

Baron, R. A. (1983) Behaviour in Organisations: Understanding and Managing the Human Side of Work.

Boston: Allyn and Bacon.

Coakley, J. (1990) Sport in Society: Issues and Controversies. St. Louis, Missouri: Moseley College.

Cushman, G. (1989) Trends in Sports in New Zealand. Kamphorst, T. .J. and Roberts, K. (Eds) Trends in Sports: A multinational Perspective. Netherlands:
Giordano Bruno Culumberg: 133-147.

Deci, E. L. and Ryan, R. M. (1985) Intrinsic Motivation and Self-determination in Human Behaviour. NY: Plenum.

Farrar, W. (1977) How to Win Contests Without Really Trying. Agricultural Education, 50(3), 53-54.

Handy, C. (1985) Understanding Organisations. Harmondsworth: Penguin Books Ltd.

Hofstede, G. (1994) Cultures and Organisations. Glasgow: Harper Collins.

Lowe, K. I., Lynch, G. A., Stone, J. A. and Kirton, I. F. (1992) Wilson, G. F. (Ed). The Tui Dairy Farmer of the Year Competition. 1992. Dairyfarming Annual, Vol 44. Palmerston North: Massey University.

McDougall, B. (1995) Trustbank Skellerup Young Farmer of the Year- Looking to 1996. Young Country, 10: $4,23$.

Rigauer, B. (1981) Sport and Work. Surrey, NY: Columbia University Press.

Shuttleworth, J. (1990) Sport Management: Professional Preparation in New Zealand, Position Report, Wellington: Hillary Commission

Swanson, P. (1984) Agricultural Extension - A Reference Manual. Rome: F. A. O.

Wards, H. C. A. (1963) Origins and Development of YFC Movement in New Zealand. New Zealand Journal of Agriculture: 106, 237-245.

Williams, D. and Way, M. (1991) Last Side to Glory: The Golden Shears Open Championship 19611990. Christchurch: NZ Hazard Press.

Winepress, Newsletter of the Marlborough (NZ) Grapegrowers Association

\section{Author}

Rupert Tipples

Senior Lecturer

Employment Relations

Horticulture Management Group

Applied Management and Computing Division

Lincoln University

P O Box 84

Canterbury

Tipplesr@tui.lincoln.ac.nz 
Table 2: New Zealand Case Studies of Agricultural Contests.

\begin{tabular}{|c|c|c|c|c|c|c|}
\hline Title and Subjects & Major Sponsors & Duration & Aims/Learning & Extent of contest & Spectacle & Value of first prize \\
\hline $\begin{array}{l}\text { Wrightson } \\
\text { Agmardt Young } \\
\text { Farmer of the Year. }\end{array}$ & $\begin{array}{l}\text { Wrightson, Agmardt. } \\
\text { (Formerly Skellerup } \\
\text { Industries, 1969-1997). }\end{array}$ & 1969- & $\begin{array}{l}\text { Comprehensive skills/ } \\
\text { knowledge to be a } \\
\text { successful young farmer. }\end{array}$ & $\begin{array}{l}\text { From local clubs } \\
\text { through regions to } \\
\text { National finals }\end{array}$ & $\begin{array}{l}\text { Limited for skills aspects } \\
\text { but total for televised } \\
\text { aspects and final quiz. }\end{array}$ & $\begin{array}{l}\text { \$NZ 70,000 package } \\
\text { with utility vehicle, farm } \\
\text { bike, travel, fertiliser, } \\
\text { credit and clothing. }\end{array}$ \\
\hline $\begin{array}{l}\text { Lincoln University } \\
\text { Foundation Annual } \\
\text { Farmers Award }\end{array}$ & $\begin{array}{l}\text { Lincoln University } \\
\text { Foundation/ } \\
\text { Rabobank }\end{array}$ & 1983 - & $\begin{array}{l}\text { Category changes } \\
\text { annually but focuses on } \\
\text { best financial and } \\
\text { management } \\
\text { performance over last } 5 \\
\text { years and ability of } \\
\text { applicant to transfer } \\
\text { knowledge. }\end{array}$ & South Island only & $\begin{array}{l}\text { Public presentation } \\
\text { round of judging. }\end{array}$ & $\begin{array}{l}\text { \$NZ 7,500 travel award } \\
\text { to encourage successful } \\
\text { contestants to travel } \\
\text { overseas and report back } \\
\text { their acquired learning to } \\
\text { benefit other farmers. }\end{array}$ \\
\hline $\begin{array}{l}\text { Bank of New } \\
\text { Zealand National } \\
\text { Sharemilkers of the } \\
\text { Year }\end{array}$ & Bank of New Zealand & 1990- & $\begin{array}{l}\text { To demonstrate the } \\
\text { farming ability, business } \\
\text { acumen and all-round } \\
\text { skills of New Zealand's } \\
\text { Sharemilkers. }\end{array}$ & $\begin{array}{l}\text { Annual national } \\
\text { contest following } \\
\text { regional finals. }\end{array}$ & None & $\begin{array}{l}\$ N Z 38,295 \text { package } \\
\text { including cash, farm } \\
\text { bike, travel package and } \\
\text { appliances. }\end{array}$ \\
\hline $\begin{array}{l}\text { ICI Wheat } \\
\text { Growing } \\
\text { Award/ICI Crop } \\
\text { Growing Award. }\end{array}$ & ICI Rural Division & $1982-89$ & $\begin{array}{l}\text { To improve wheat } \\
\text { yields, by showing the } \\
\text { highest net return for a } \\
\text { trial. Farmers were to be } \\
\text { enabled to look } \\
\text { knowingly at their crops } \\
\text { and how they were } \\
\text { achieving their yields. } \\
\text { There was always the } \\
\text { aim of achieving the } \\
\text { highest gross margin per } \\
\text { hectare. }\end{array}$ & $\begin{array}{l}\text { Canterbury, but } 1986 \\
\text { in Southland as a } \\
\text { demonstration. }\end{array}$ & $\begin{array}{l}\text { Field days featuring } \\
\text { contestants growing } \\
\text { plots and related trade } \\
\text { exhibition. Interest fell } \\
\text { with falling prices and } \\
\text { when growers had } \\
\text { grasped the central ideas } \\
\text { of the scientists. The } \\
\text { competition subject } \\
\text { matter then changed to } \\
\text { cereals first, and then to } \\
\text { all crops. }\end{array}$ & 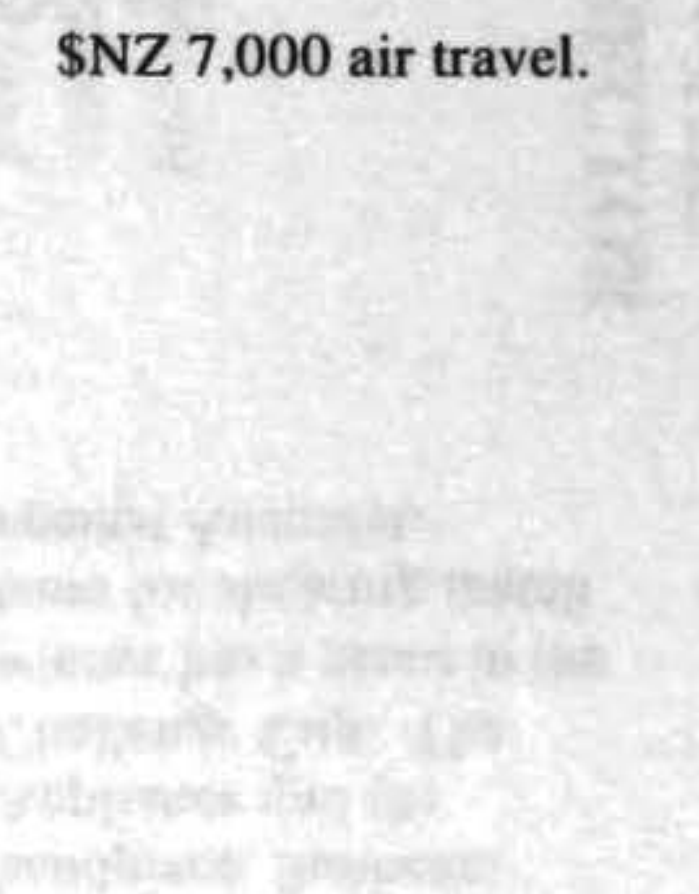 \\
\hline
\end{tabular}


Table 2. Cont.

Golden Shears Open Shearing

Dominion Breweries,

Championship

Sheep shearers

Silver Secateurs

Competition

Grapevine pruners

The Fieldays

Cyclone Golden

Pliers Fencing

Competition

(singles)

Fencers Sunbeam Agrisales,

Sandvik, Fruitfed

Supplies and Cyclone

Fencing.

1960- When started after

WWII shearing

competitions were

designed to raise the

quality of shearing and

wool handling to

improve the international

economics of the wool

clip, and the status of

shearers/ wool handlers.

The Golden Shears was

set up as a World

Championship.

1994-

To improve standards of pruning and tying vines, and improve the status of pruners/tiers.

Cyclone Fencing.

$1969-$

To encourage higher quality standards,

benefiting both the

fencing industry and the farmer.
Only at Masterton,

Wairarapa, NZ, bu

there are major

shearing competition

circuits in both South

and North Islands.

Began regionally in

Marlborough, but has

moved around NZ

associated with NZ

Grapegrowers'

Council's annual

Bragato conference.

Local competitions

lead on to an

international

championship.
Finals are held before an

audience in the

Memorial Hall.

Promoters now have a

major task promoting the

event as a spectacle and

getting spectators

through the doors.

Not easy to see because

of the row nature of

vineyards. Some

spectators were

supporters, other

wished to learn from

'experts'.

\section{Good. Fencing}

competitions are regular

Agricultural Field Days

events.
$\$ N Z 2,000$ plus a Sunbeam

handpiece, Sunbeam

Appliance and the

Challenge Cup. The

winner has a place in the

team for shearing match

against Australia.

\section{$\$ N Z 600$}

$\$ N Z 5,000$ plus a Stihl

chainsaw and the Golden

Pliers Trophy. 